\title{
Estrategias de difusión de la cultura física en Argentina. El caso de un colegio de elite del oeste del Gran Buenos Aires entre 1946 y 1955
}

Diffusion Strategies of Physical Culture in Argentina. The Case of an Elite College in the west of Gran Buenos Aires, between 1946 and 1955

Iván Pablo Orbuch ${ }^{1}$

\section{Resumen}

\begin{abstract}
La cultura física adoptó un inusitado vigor en Argentina entre 1946 y 1955, en ocasión de las presidencias de Juan Domingo Perón. En ese lapso se realizaron torneos infantiles, intercolegiales destinados a los alumnos del nivel secundario y certámenes internacionales como los primeros Juegos Panamericanos. ¿Influyeron estas políticas al interior de las instituciones educativas? En este caso, en el abordaje de un colegio al que asistían sectores de elite pueden detectarse algunas particularidades como el amplio espacio disponible para las prácticas deportivas, la formación de una fuerte identidad vinculada a la institución y la difusión de ciertos valores de la cultura física. Una revista estudiantil será la fuente que permitirá ver como se tradujo el pasaje de una política nacional al interior de una institución educativa.
\end{abstract}

Palabras clave: cultura física, Argentina, colegio de élite

\section{Abstract}

Summary: Physical culture adopted an unusual vigor in Argentina between 1946 and 1955, on the occasion of the presidencies of Juan Domingo Perón. During this period, children's and intercollegiate tournaments were held for secondary school students and international competitions such as the first Pan American Games. Did these policies influence the educational institutions? In this case, when approaching a school attended by elite sectors, some particularities can be detected such as the wide space available for sports practices, the formation of a strong identity linked to the institution and the diffusion of certain values of physical culture. A student magazine will be the source that will allow us to see how the passage of a national policy was translated into an educational institution.

\section{Keywords: physical culture, Argentina, elite school}

${ }^{1}$ Universidad Nacional de Hurlingham. Instituto de Educación. Correo electrónico: ivan.orbuch@unahur.edu.ar 


\section{Introducción}

La presente investigación busca profundizar en las estrategias de difusión e implementación de la cultura física en un colegio al que asistían sectores de elite en Argentina en el oeste del Gran Buenos Aires². El periodo escogido, entre 1946 y 1955, no resulta fortuito. En ese lapso Juan Domingo Perón regía los destinos nacionales. Fue allí cuando la cultura física fue pensada como un derecho individual con connotaciones colectivas puesto que desde la perspectiva estatal el sacrificio personal tributaba a los intereses colectivos tornándose visible en la necesidad de contar con ciudadanos sanos y fuertes que engrandecieran a la nación. Es por ello que este trabajo buscará pistas que vinculen el contexto general argentino con el particular que se vivenciaba en una institución educativa. De allí la importancia del concepto de cultura escolar, que remite a una lógica propia en las escuelas, y la relevancia de realizar una descripción de la institución escogida, que, para reforzar su particularidad, contaba con un periódico estudiantil en donde se reflejaban las vicisitudes cotidianas del ámbito escolar.

En virtud de lo expuesto, este trabajo será dividido en cuatro secciones. En la primera se buscará describir el concepto de cultura escolar, a fin de dar cuenta de las especificidades vinculadas al ámbito estrictamente educativo. En el segundo se realizará una descripción del colegio escogido con el propósito de recalcar sus principales características que hicieron de ese establecimiento educativo uno de los más elegidos de su tiempo. En el siguiente se analizará lo acaecido durante el gobierno peronista respecto a la cultura física con la finalidad de demostrar el auge propiciado por diversas políticas estatales. Por último, se analizará lo sucedido con la cultura física en el colegio mencionado a través de una fuente primaria como lo era una revista realizada por los estudiantes.

\section{Cultura escolar}

En los últimos años, en el ámbito de la historiografía de la educación, surgió con fuerza el concepto de cultura escolar como aquel que permitía adentrarse en los procesos ocurridos dentro de los muros escolares. De esta manera, cuestiones como las normas, los valores de las instituciones, los rituales característicos, los actores de la comunidad educativa y su interrelación, fueron analizadas desde diversas perspectivas interdisciplinarias.

Una de esas corrientes, fue la liderada por Dominique Juliá (2001: 12) quien definió a la cultura escolar como "un conjunto de normas que definen conocimientos a enseñar y conductas a inculcar, y un conjunto de prácticas que permiten la transmisión de esos cono-

\footnotetext{
${ }^{2}$ Agradezco a las autoridades del Colegio Ward que me hayan permitido ingresar a su archivo histórico.
} 
cimientos y la incorporación de esos comportamientos: normas y prácticas coordinadas a finalidades que pueden variar según las épocas".

Desde esta mirada, el ámbito escolar no se planteó sólo como un espacio contenedor de saberes, sino como aquel que podía resignificarlos, dándoles un marco de construcción por medio de las asignaturas escolares. Precisamente, Antonio Viñao (1995) sostiene que estas son una de las creaciones más relevantes de la cultura escolar, en tanto son dinámicas y constituyen espacios de poder. Desde esta perspectiva, es en las asignaturas adonde se dirimen diversas pujas en la cual se condensan los actores, las estrategias y las acciones.

El concepto de cultura escolar es útil para el presente trabajo porque demuestra que entre las normas y lo sucedido al interior de las instituciones educativas suele haber diferencias. Como enfatiza Stephen Ball (1990), los efectos de las políticas no son solo el mero cumplimiento de los objetivos propuestos por esta, sino el resultado de la sumatoria de acciones donde intervienen diversos actores sociales con distintas posiciones políticas. En palabras de David Tyack y Larry Cuban (1995: 25), si bien "fuerzas externas dirigen el curso de la reforma escolar, las escuelas también son, en ciertos aspectos, instituciones autónomas y protegidas"

\section{Acerca de la escuela}

La institución educativa destinataria de la presente investigación, el Colegio Ward, tiene más de 100 años de vida. Fundado en 1913, su sede original se encontraba en el barrio de Flores, perteneciente a la Capital Federal. En la actualidad, si uno visita su página web, puede leer que se presenta a sí misma como un colegio cristiano abierto a la comunidad. Creado gracias a la donación de un filántropo estadounidense, contó con el apoyo de la Iglesia Metodista local y de la Iglesia de los Discípulos de Cristo. En su acta fundacional, quedaron en claro los propósitos educativos prioritarios, que eran ser "un colegio cristiano, de continua inspiración democrática, que sirviera de puente entre las dos Américas". Desde 1933 se encuentra en su actual ubicación. Una finca situada en Villa Sarmiento, perteneciente al municipio de Morón, en el oeste del Gran Buenos Aires. En sus inicios, tenía un régimen de pupilos, semi pupilos e internado.

El colegio era mixto, su alumnado perteneció a los sectores acomodados de la zona, y la institución puede definirse como una de elite, de acuerdo al concepto esbozado por Michael Pincon y Monique Pincon Charlot (2010).Siguiendo a estos autores, puede afirmarse que estas instituciones están compuestas por sectores sociales que combinan 4 tipos de atributos: capital económico, es decir posesiones; capital social (relaciones interpersonales); capital simbólico, es decir la posesión de status, un apellido relevante y prestigio; y capital cultural, incorporado, objetivado o institucionalizado. Sea para mantener o incrementar esta posesión de capitales diversos, la elección de las instituciones juega un rol central para las familias. 
Para Guillermina Tiramonti y Sandra Ziegler (2008: 15), esta cuestión puede denominarse estrategia de vida, dado que:

la elección escolar no es solamente parte de la libertad dentro de una racionalidad capitalista, sino que más bien, supone el interjuego entre la historia biográfica de los individuos, la historia de sus familias y las posibilidades concretas de elección en un mercado de opciones fuertemente fragmentado.

Sí bien el currículum era el dispuesto por el entonces Ministerio de Justicia e Instrucción Pública (recién a partir de 1949 se creó el Ministerio de Educación de la Nación), estas instituciones propusieron adicionalmente programas que contribuían a forjar diferencias con otras instituciones educativas de la época. Algunas de ellas eran presentadas como actividades extraescolares, programas internacionales de idioma inglés, y, aprovechando el amplio espacio disponible, la institución seleccionada para la presente investigación le daba un amplio espacio a diversas actividades deportivas. Torneos internos, competición con otras instituciones en los torneos intercolegiales, entre otros, eran parte de las actividades fuertemente promocionadas en el folleto que circulaba en la zona para interesar a potenciales alumnos. El prospecto del año 1951 del Colegio Ward constituyó un buen ejemplo de lo aseverado. Con 37 páginas e ilustrado de numerosas fotos a color, lo que no era una práctica habitual en la época, puede leerse que el colegio se edificó en:

un antiguo y magnífico parque cuyos frondosos árboles ciñen en un abrazo de armonía y de belleza, una moderna edificación al servicio del alumno. La vida entre las plantas que apuntan siempre hacia arriba como indicando el camino mejor, dan un sentido de sereno optimismo y tienen la virtud de tonificar el cuerpo y fortalecer el espíritu (Prospecto, 1951: 2).

La educación corporal, entonces, aparece en el folleto publicitario como una de las herramientas destacadas con el propósito de atraer nuevos estudiantes. En ese sentido, el desarrollo de "un cuerpo sano, fuerte y armonioso" (1951: 3), era un aspecto fundamental de la educación integral que la institución ofrecía a la comunidad. 


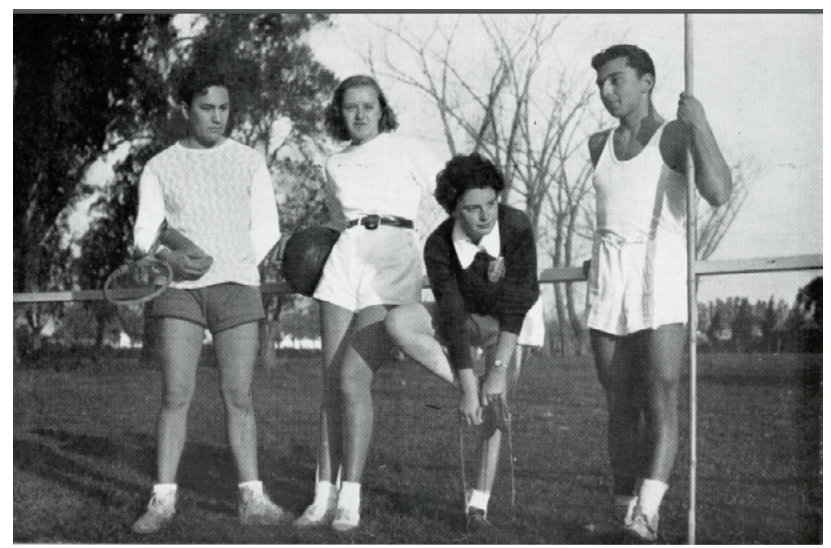

Imagen Prospecto año 1951: 8.

Puede apreciarse en la imagen, titulada en el folleto original como Ideal Deportivo, a 4 jóvenes, 2 hombres y 2 mujeres en perfecto estado físico y practicando los más disímiles deportes: garrocha, tenis, básquet y atletismo. Se hacía referencia a que el viejo aforismo Mente sana en cuerpo sano se cumplía en la institución, constituyendo uno de los puntos nodales del esquema educacional. El folleto subrayó que "los juegos atléticos que dan elasticidad al cuerpo y contribuyen a la formación del carácter son practicados en forma científica en todos los cursos y bajo dirección especializada" (1951: 4). Asimismo, se enfatizó que el ideal institucional era realizar todos los deportes posibles por el solo hecho de hacerlos y por los efectos benéficos que redundaban en una sustancial mejora de la salud física. "Efectos que rinden en salud física, en el hecho de estar permanentemente al aire libre, en contacto con el sol, en un ambiente sano, acorde a lo valores pregonados por la institución" (1951: 4).

Como en la Grecia clásica miramos los juegos atléticos como una exhibición de vigor, de destreza del cuerpo dominado por el espíritu, donde puede más el juego mismo, la sobriedad y la templanza que el anhelo de ganar, aunque sea esta una aspiración legítima (1951: 16).

Por los motivos expuestos es que todos los alumnos, de primaria y secundaria, de ambos sexos y en especial los internos debían participar en las diversas competencias organizadas por el Departamento Física de la institución. A tales efectos, todos los estudiantes eran sometidos a un riguroso examen médico previo a las justas deportivas, "lo que asegura una correcta aplicación de las más modernas teorías en la especialidad" (1951: 9).

La institución también contaba con un moderno Gimnasio, que en ocasiones especiales como ser algún aniversario de la institución o la conmemoración de las efemérides escolares 
hacía las veces de Salón de actos. El Gimnasio-Salón de actos, fue inaugurado el 17 de junio de 1950, y llevaba el nombre de un ex alumno, quien había fallecido siendo aún muy joven: Guido Festa. El ex estudiante, según se lee en el folleto, era un destacado deportista en variadas especialidades y siempre había defendido de manera exitosa a la institución. La importancia de la cultura física puede apreciarse, además de lo ya mencionado, en que en el folleto aparecía con más imágenes que la Clínica médica escolar, fundada en 1933. Asimismo, su espacio es más relevante que las diversas manifestaciones artísticas realizadas en la institución como el teatro y la utilización de instrumentos como el piano, violín, guitarra y teclado. El Departamento Comercial y que la enseñanza del inglés, cuestión esta última que realzaba el prestigio institucional, también se ven desdibujada ante el espacio otorgado a la cultura física.

\section{Cultura física en el peronismo}

Si ejercitar el cuerpo fue sinónimo de fortalecer la nación, tal como demostró Pablo Scharagrodsky (2008), en pocos períodos de la historia argentina esto se tornó tan visible como en el comprendido entre 1946 y 1955. En los años en que Juan Domingo Perón fue dos veces electo presidente de manera democrática, la preocupación por el desarrollo de una cultura física destinada a toda la sociedad alcanzó ribetes dignos de consideración, principalmente porque la entronizó a la par de otras manifestaciones culturales de mayor arraigo en el imaginario social nacional. Fue de esta manera que el proyecto político peronista encontró en el fomento a la educación de los cuerpos los argumentos legitimadores para transmitir un ideario respecto a conceptos centrales para su cosmovisión política tales como patria, comunidad y sociedad. El gobierno peronista se ocupó de realizar torneos infantiles, intercolegiales e incluso certámenes internacionales de relieve como los primeros Juegos Panamericanos en el año 1951.

A los fines metodológicos cabe mencionar que tres conceptos estarán presentes en la presente investigación de un modo recurrente: cultura física, Educación Física y deportes. Los mismos aparecen indistintamente en la revista estudiantil. Vale la pena aclarar que si bien es cierto que existen las taxonomías y los diccionarios, en algunas ocasiones los términos utilizados son ajenos a cristalizaciones que se prolonguen de modo indefinido en el tiempo. Por ese motivo, cabe aclarar que la aparición en los documentos del concepto de cultura física es propia del lenguaje de la época de estudio, y si bien se venía utilizando desde fines de siglo XIX en el plano nacional e internacional, tal como menciona Jacques Gleyse (2011), es entre 1946 y 1955 que pasó a formar parte del vocabulario cotidiano en Argentina. Fue así que el uso del concepto de cultura física fue funcional al gobierno peronista para evadirse de 
un debate específico del campo de la Educación Física respecto a la pertinencia de su utilización.

Como menciona Ángela Aisenstein (2006), la cultura física es una forma de discurso especializado que se vincula con una construcción de significados centrados en la Educación Física y los deportes, siendo este trabajo deudor de esta interpretación. En esa dirección, puede afirmarse que su utilización es más abarcativa que la habitual asociación con la Educación Física porque la distingue de la vertiente escolar, y la asimila a una parte neurálgica de la cultura general que todo individuo debía poseer, del mismo modo en que fue pensada, por ejemplo, en el Segundo Plan Quinquenal esbozado y planificado por el gobierno peronista. Allí puede leerse que la cultura física se encontraba en la selección realizada por los funcionarios encargados de la planificación estatal a la par de la cultura literaria, científica, artística, tradicional, histórica, cívica y del patrimonio cultural. Esta consideración es indicativa de su nuevo lugar protagónico y de su transformación en una razón de Estado (Segundo Plan Quinquenal, 1953).

Así, paralelamente a una idea que sostenía que la salud individual reforzaba la salud de la población, y que la fortaleza de cada uno contribuía al desarrollo nacional, se puede identificar un discurso político que hacía de la cultura física un derecho individual, a la par de una responsabilidad del Estado y del conjunto de la sociedad.

Respecto a la Educación Física, puede mencionarse que la misma se constituyó como una disciplina moderna estrechamente vinculada a la formación y desarrollo de los sistemas educativos nacionales. En el caso argentino esto se encontró asociado a la sanción de la Ley 1420 en el año 1884. Empero, la legislación que dio inicio formal al sistema educativo nacional no significó necesariamente el comienzo de los sentidos lógicos de la disciplina, tal como planteó Eduardo Galak (2012):

\footnotetext{
Es necesario observar cómo nace producto de la legislación estatal el denominado sintagma "educación física", se rastrean aquellos procesos que producen, primero, prácticas, para luego dar paso a los mecanismos de su reproducción; de allí que surja la necesidad de un oficio capaz de (re)transmitir dichas prácticas. Como corolario de este desarrollo emerge el llamado oxímoron "Educación Física" (2012: 8).
}

La Educación Física transmite, produce y reproduce modelos de comportamiento, de sensibilidad y de racionalidad indisociables "de una cultura, con sus respectivos recursos técnicos, emocionales e ideológicos. Es, en ese sentido, un poder; un poder que se ejerce sobre el cuerpo de los demás" (Beer, 2014: 10).

Por su parte, el surgimiento de los deportes, fue un proceso que arrancó al final del período decimonónico y su masividad fue dándose conforme avanzaba el lapso en que 
indagará este artículo. Por caso, Norbert Elias (1992) estudió lo acaecido en Inglaterra, donde observó que desde sus orígenes los deportes fueron utilizados por las elites para gobernar los cuerpos de la propia clase alta. En Argentina, el proceso fue similar. Los primeros clubes donde los deportes se practicaban fueron de los denominados caballeros pertenecientes a los sectores acomodados de la sociedad, como aquellos donde se practicaba esgrima o tiro, por citar algunos de ellos. Con la irrupción de la llamada cultura de masas, los deportes se masificaron y pronto se transformaron en un elemento destacado de la sociabilidad. Cabe precisar que, como señala Ana Torrón (2015), el deporte contemporáneo es, desde hace más de cien años, un campo de intervención específico de la Educación Física, a la vez que un fenómeno que excede ampliamente a esta disciplina.

Es importante mencionar el hondo calado que los deportes pueden alcanzar como herramientas educativas destinadas a los jóvenes, de ahí su paulatina introducción en los planes de estudio, y, como se analizará, en la cotidianeidad escolar.

Considerando la centralidad que estos tres conceptos tuvieron en la educación de los cuerpos entre 1946 y 1955, abordaré como robustecer el cuerpo, la mente y el espíritu fue interpretado como un sinónimo de fortalecer la Nación cuyas implicancias pueden analizarse en lo sucedido al interior de las instituciones educativas.

\section{Revista The International}

A la hora de comprender el peso que la cultura física tuvo en la propuesta educativa del Colegio Ward, una fuente primaria de interés resulta la Revista The International, publicada por los estudiantes de la institución. En ese sentido, su análisis se presenta como pertinente para indagar en las estrategias de difusión de la cultura física. Vale la pena señalar que los periódicos escolares ideados, producidos y escritos por los alumnos, permiten tener un panorama de conjunto del ámbito escolar y del ámbito juvenil. Permiten "reconocer representaciones, intereses, gustos y preferencias de ambos universos escolares" (Finocchio, 2013: 8).

Es importante mencionar que The International, surgida el 26 de abril de 1918, no fue una publicación más, comparándola con otras revistas elaboradas por estudiantes. La calidad de la impresión de la publicación pergeñada por los alumnos del colegio de elite del oeste del Gran Buenos Aires era sustantivamente superior. A su vez, a tono con la pertenencia social de sus integrantes, la misma contaba con el apoyo de importantes empresas nacionales e internacionales, en las cuales se desempeñaban los padres de quienes concurrían allí. Una de esas empresas era la petrolera Esso, que en todos los números revelados entre 1946 y 1955 , contaba con una página de publicidad. La prestigiosa Editorial Kapelusz fue otro de los célebres anunciantes que podían leerse. La aerolínea Panamerican, Yerba Mate Taragui y Frávega, una reconocida casa de electrodomésticos, eran otro de los frecuentes avisadores. 
Asimismo, numerosos negocios de la zona, entre los que se encontraban inmobiliarias, farmacias, confiterías y sanatorios, en su mayoría propiedad de parientes de los alumnos, dan cuenta del poderío económico de las familias que decidían mandar a sus hijos a la citada institución. La publicación estaba integrada por un consejo directivo compuesto por cuatro personas en los roles de director, vice director, consejero y administrador. También contaba con redactores, correctores, fotógrafos, mecanógrafos, dibujantes y encargados del área de publicidad.

En lo concerniente al contenido, en las páginas de la revista pueden apreciarse las numerosas actividades realizadas en el colegio tanto en el nivel primario como secundario, siendo el espacio para las realizadas por estos últimos mucho más amplio. Cabe mencionar que todas esas actividades estaban reglamentadas por las distintas sub comisiones formadas por los alumnos. En el nivel primario pueden citarse a la sub comisión de cultura, de prensa, de orden, de deportes y de deportes femeninos. En el nivel secundario pueden nombrarse a las subcomisiones de cultura, de señoritas, de orientación, del internado, de cinematografía, de deportes y el Cosmopolitan Club, que estaba compuesta íntegramente por estudiantes extranjeros.

\section{Cultura física en el colegio}

Analizando The International puede apreciarse el relevante papel que tuvo la cultura física dentro de las actividades realizadas por los estudiantes. Edición tras edición, el espacio de esta va tornándose más relevante, al tiempo que las fotografías y coberturas de los eventos también ganan centimetraje. Cabe señalar que cuatro son las cuestiones a profundizar en el presente abordaje: la cultura física femenina, lo festivo vinculado a las diversas manifestaciones deportivas, la visita de equipos y figuras deportivas relevantes que brindaban exhibiciones o disputaban justas y la existencia de recurrentes notas sobre cuestiones morales vinculadas a la cultura física.

En lo atinente a la cultura física femenina, el seguimiento de las diversas actividades en que participaban mujeres tuvo un amplio espacio al interior de la publicación, en coincidencia con lo sucedido con el advenimiento del peronismo al poder (Orbuch, 2018). Por caso, en 1946, y con el sobrio título de Sub campeonas se hizo referencia a la gran campaña realizada por las chicas del equipo de volley ball, quienes habían participado por primera vez de ese torneo y lograron escalar hasta la final disputada en el Buenos Aires Lawn Tennis Club el día 31 de agosto del citado año. "Los que hemos seguido de cerca a nuestro equipo representante pronto nos dimos cuenta que poseían grandes condiciones como para ocupar un puesto en la colocación final" (The International, 1946: 11). Los elogios en la nota fueron prolíficos y se hizo referencia a que las alumnas habían competido con hidalguía y con el 
propósito de dejar en alto el nombre y prestigio de la institución. Para llegar al último partido con chances de obtener el título, las alumnas del colegio vencieron sucesivamente a sus pares de la Escuela Normal N 5, Normal N 10, Normal Mixto de Campana y a la Escuela Normal $N^{\circ}$ 6, perdiendo la final con las chicas de la Escuela Normal $N^{\circ} 1$, en el tercer set, lo que "da cuenta de la igualdad de fuerzas. Venció el que tuvo más suerte" (The International, 1946: 11).

El día del partido decisivo, se hizo presente el Director General de Educación Física, César Vázquez, quien ya ocupaba ese cargo antes de la llegada del peronismo al gobierno. La importancia del evento deportivo puede apreciarse en que sus resultados fueron seguidos por el Boletín de Comunicaciones, que era el órgano de difusión del quehacer del Ministerio de Justicia e Instrucción Pública. En efecto, allí puede leerse que, aparte de las escuelas que ocuparon los dos primeros lugares, la tabla fue completada por el Normal $\mathrm{N}^{\circ} 4$, el Normal $N^{\circ} 10$, ambos en la Ciudad de Buenos Aires. El quinto y sexto lugar lo ocuparon el Normal de Quilmes y el Normal de Campana. A su vez, se dispuso que las vicisitudes de este torneo debían aparecer en el programa que iba a repartirse en la Fiesta de la Educación Física a desarrollarse en octubre de ese mismo año, así como en la Memoria del año de la Dirección General de Educación Física (Boletín de Comunicaciones n79, 1946).

En la revista The International, en otro apartado llamado Impresiones del partido intercolegial de Volley-ball firmado por S. Derka, se hizo referencia a lo acontecido ese día, haciendo hincapié en la presencia del nombrado funcionario César Vázquez, y del Vice Director General de la institución, Mrs. Mac Williams. Luego, el informe se centró en contar el desarrollo del match.

La participación femenina también se dio en el pentatlón. En 1953, en los torneos intercolegiales impulsados por el gobierno peronista que contaron con la participación de cerca de 90 colegios y más de 200 competidoras: "la actuación de nuestras chicas dejó mucho que desear en comparación a lo que están acostumbradas a hacer" (The International, 1953: 36). Empero, demostraron un fuerte espíritu deportivo y fueron felicitadas por los cronistas de la revista estudiantil por ello.

La nota nuestras chicas y el deporte, aparecida en la edición de 1947, profundizó estos tópicos y desplegó argumentos legitimadores de la intervención femenina en diversos deportes. Allí se invitó a las alumnas a ser parte de la sub comisión de deportes y a anotarse en la actividad de su preferencia, dado que "las chicas pueden desempeñarse sin problemas en el deporte que ellas elijan puesto que en el colegio hay espacio de sobra para que eso suceda y el deporte es una escuela de vida que es preciso conocer" (The International, 1947: 25).

Precisamente, los valores asociados a la práctica de los deportes fueron un tópico repetido al interior de la publicación, coincidente con las manifestaciones oficiales en ese sentido. En ambos casos, la prédica respecto a la importancia de ganar con honra y perder con hidalguía evidenció una campaña pedagógica de tintes moralistas que buscaba contribuir 
en la educación de amplios sectores sociales. En la nota titulada Un aspecto social del fútbol olvidado se hizo hincapié en lo relevante que resultó para la juventud la ley de descanso dominical sancionada en agosto de 1905. Según se lee en The International, hasta ese momento, los domingos eran días en que los jóvenes tomaban las calles y los bares de la ciudad con resultados calamitosos para las buenas costumbres ciudadanas. "Como era muy generoso el expendio y el consumo de bebidas alcohólicas, en las susodichas reuniones sociales, libaban copiosamente tales licores con grave perjuicio para su salud física y moral" (The International, 1945: 7). Pese a que en los primeros tiempos el fútbol era visto con desconfianza por numerosos sectores sociales, dado su origen inglés, muy pronto fue apropiado como el deporte más popular del país adoptando:

contornos nacionales y empieza a realizar su obra de higiene social sustrayendo el vicio alcohólico: un tanto mitigado por la ley dominical aludida, pero que seguía siendo grave a multitudes que en lo sucesivo se congregarían en amplios estadios para contemplar un espectáculo interesante, ameno y en campos sanos al aire libre (The International, 1945: 7).

Otra acción en torno de la moralización de la juventud mediante la cultura física la dio el tradicional encuentro que se disputaba entre alumnos y ex alumnos de la institución. Las finalidades de estas justas deportivas eran varias. Por un lado se reforzaba el sentido de pertenencia a la institución. Por el otro, se recreaba un "hermoso espíritu de camaradería" (The International, 1946: 8) entre todos los competidores. A su vez, solía haber una especie de tercer tiempo, similar al implementado luego de los partidos de rugby, adonde se departía y comía entre todos los jugadores. Esa tradición se mantuvo inalterable, salvo en 1946 y desde las páginas de la revista lo recordaron de modo irónico: "una cosa debemos comentar: el té que otras veces fue servido y que es un medio para estrechar vínculos y repara energías, este año no fue servido. No olviden este detalle" (The International, 1946: 8).

En línea con los valores moralizadores alrededor de la cultura física, la Subcomisión de deportes de la institución tenía un lema: triunfo sin orgullo, derrota sin amargura. Precisamente, el precursor de esas palabras fue el docente de Educación Física Jonatan Pardías, quien solía aparecer en las notas de la publicación vertiendo diversos conceptos pensando a la cultura física como una actividad esencialmente moralizadora. Como se aprecia, había un especial énfasis en generar competidores que practicaran el deporte por el deporte mismo. La revista subrayó que a lo largo de las actividades programadas en el año 1948, "el espíritu deportivo y caballeresco que siempre ha caracterizado a nuestros equipos, no fue desmerecido en ningún momento" (The International, 1948: 9). Esta perspectiva fue resaltada en ocasión de las diversas ediciones del Torneo Atlético que se disputaba año a año. Por caso, en la cobertura de 1952 se destacó que "fue un día de gala pues se demostraron y destacaron los 
valores que él deporte posee, tanto entre los varones como entre las niñas" (The International, 1952: 8). La particularidad del torneo fue que aquellos deportistas que ganaran en sus competencias respectivas se hacían acreedores a un pullover gris con las iniciales de la institución, siendo esa obsequio muy requerido por los alumnos. A su vez, el interés del público asistente se daba porque ellos sabían que "iban a presenciar el deporte como debe ser: limpio, sano y honrado" (The International, 1952: 9).

La publicación contaba con ilustraciones en tono humorístico, tal como se observa en las imágenes.
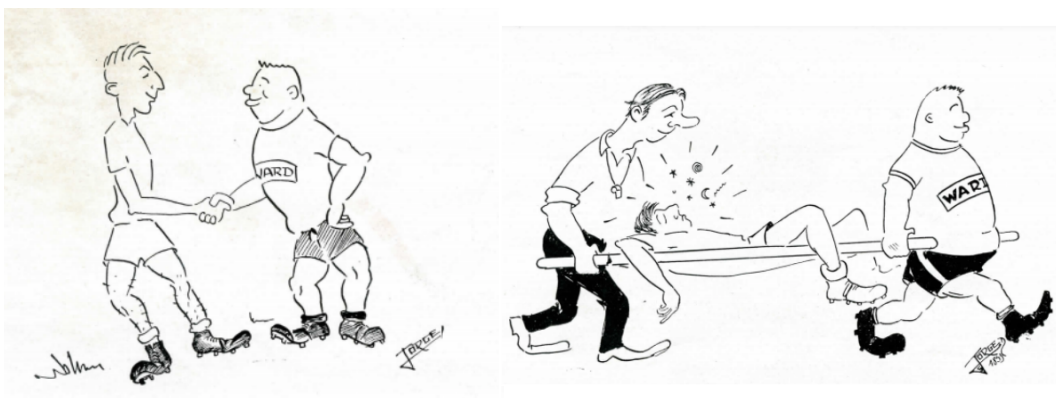

Tira cómica. Revista The International, 1953: 35.

Allí pueden apreciarse los valores de amistad y respeto a los rivales en clave humorística: luego de un saludo cordial, y un choque provocado por la fortaleza física de los estudiantes de la institución, el mismo alumno, orgulloso y solícito, lleva en camillas a su rival lastimado.

Por su parte, lo festivo puede apreciarse en diversas actividades, pero en especial en las palabras de los propios estudiantes. Por caso, Josúe Julio Grau, en la columna Mi opinión, resaltó las bondades que él consideraba que poseía la institución. Allí, hizo mención a que conoció el colegio hace muchos años, y que desde afuera de la institución había escuchado de sus ideales, principios y objetivos educativos, aunque nunca imaginó que estos eran tan elevados. Destacó la educación integral, que era el objetivo de las autoridades. En ella, se encuentran la educación intelectual, la educación moral y la educación física. Precisamente, es de esta última la que mayores referencias brindó el joven estudiante. Grau exaltó el papel de "nuestra fiesta deportiva máxima" (The International, 1948: 25), el Torneo Atlético Anual. Allí competían entre sí, en un marco de camaradería:

decenas de jóvenes, limpios, puros, optimistas, seguros de sí mismos, que se han estado preparado durante semanas dando de sí todo para lograr una marca, para llegar a su ideal, recibiendo como premio una cinta, pero que involucra el respeto, el aprecio, la estima de todos sus compañeros, de todo el Colegio (1948: 25). 
Grau comparó a la competición con los atletas de la Grecia Antigua, sitio en el que la adquisición de la cultura física jugaba un rol tan destacado, ya que la educación era para la vida, y para formar un hombre completo.

En virtud de sus logros deportivos, la institución solía ser parte de la Fiesta de la Educación Física ${ }^{3}$ que se llevaba adelante en forma ininterrumpida desde el año 1944. Por caso, en la edición del año 1950, el colegio se hizo acreedor de la copa al imponerse en los torneos intercolegiales de volley ball. "Es esta reunión de deportistas, una de las más simpáticas en su género, ya que allí se reúnen varios miles de estudiantes que desfilan, y reciben sus premios, sí a ellos se hicieron acreedores" (The International, 1950: 41). En las imágenes se puede apreciar a la multitud presente en el estadio del club River Plate, y a los equipos femenino y masculino representativos del colegio.

Otra de las facetas vinculadas a la difusión de la cultura física en la institución puede apreciarse con la visita de conocidos equipos y reconocidas figuras de diversas disciplinas. Uno de esos emblemáticos ejemplos ocurrió en ocasión de la visita de la Mutual Veteranos del Club Atlético River Plate, el equipo de fútbol más importante de Argentina. La cobertura del evento en las páginas de The International lo resumió con una nota titulada, en letras pequeñas, DÍA DE FIESTA PARA NUESTRA ESCUELA: River Plate nos visita. Fue así que el sábado 18 de octubre de 1947, como parte de la campaña para juntar fondos para el Gimnasio y Salón de Actos se produjo el encuentro entre los ex jugadores del club riverplatense y los ex alumnos de la institución. Sí bien estos últimos eran mucho más jóvenes y se esperaba mayor paridad en la justa, lo cierto fue que:

numerosas sonrisas un poco escépticas se transformaron en admiración, ante las acciones perfectas de hombres que pisando los cincuenta años de edad, equiparaba sus energías con jóvenes de veinticinco, equilibrando la lentitud física, propia de los años con la rapidez mental (The International, 1947: 37).

River Plate se impuso por 4 tantos a 1 en el partido, y en su equipo se desempeñó el "Sr. Oliva, quien abrió el marcador y es profesor de nuestra casa" (1947: 37). El encuentro preliminar fue disputado entre el equipo oficial del colegio y el Comercial de Ramos Mejía, demostrando que nadie quería perderse la cita de apreciar en vivo a leyendas del fútbol argentino.

Otra importante visita que adoptó ribetes celebratorios se produjo cuando el equipo Maravillas del patín se hizo presente en la institución en los años 1953 y 1954. La exhibición en ambos casos se realizó en el Gimnasio y Salón de Actos Guido Festa y contó con la asistencia de numerosas personas que presenciaron un "espectáculo movido y agradable

\footnotetext{
${ }^{3}$ Un estudio de la Fiesta de la Educación Física puede encontrarse en Orbuch, Iván. (2016). Peronismo y Educación Física. Políticas públicas entre 1946 y 1955. Buenos Aires: Miño y Dávila.
} 
gracias a la calidad de los integrantes de la troupe" (The International, 1954: 31). Luego del evento se sirvió un té que culminó con las palabras del presidente del centro y del director de la institución. El señor Fernando Nogués, director e intérprete del grupo, dijo que gustoso aceptaría volver a la institución a realizar otra exhibición gimnástica.

Por su parte, el célebre corredor de automovilismo, Juan Manuel Fangio también se hizo presente en la institución. Lo hizo el 16 de octubre de 1950. El motivo de su visita fue brindar una conferencia destinada a la comunidad educativa. No llegó sólo, lo hizo acompañado del conocido relator Luis Elías Sojit, de Roberto Mieres, otro conocido automovilista de la época, del Director Técnico Amadeo Bignami y de otras personalidades del mundo automotor. Según la crónica efectuada por la revista, "Fangio expresó la grata impresión de encontrarse en nuestra institución, contestó además a algunas preguntas formuladas por los alumnos, siendo objeto de un interesante reportaje" (The International, 1950: 25). Cabe mencionar que en la sección veredictos colegiales, donde aparecían las actividades, comidas, libros y deportistas favoritos de la institución, Fangio, ocupó junto a Furlong, el campeón mundial de básquet, el sitial de privilegio. Luego de retirarse Fangio, Sojit hizo uso de la palabra, emocionando con sus relatos a todos los asistentes.

El deseo de los alumnos de la institución se hizo realidad en el año 1952 cuando el equipo de Gimnasia y Esgrima de Villa del Parque, en donde Guillermo Furlong participaba desde 1944, enfrentó a su similar de Palermo en el Gimnasio del colegio ante una importante cantidad de público asistente (The International, 1952). Entre los invitados, Luis Elías Sojit nuevamente se hizo presente y se encargó de los relatos del encuentro entre ambos representativos.

Todas estas visitas fueron tomadas por los asistentes como fiestas del deporte, según se lee en las páginas de la publicación estudiantil. Algo similar ocurrió en el año 1947, cuando se realizó un festival de básquet para juntar fondos para la construcción del Gimnasio y Salón de Actos. Fueron de la partida cuatro prestigiosas instituciones: River Plate, Boca Juniors, San Lorenzo de Almagro y Gimnasia de Esgrima de Vélez Sarsfield. "Pese a lo destemplado del día y una fugaz llovizna, gran cantidad de público se congregó para presenciar el desarrollo de los distintos partidos que se jugaron en un ambiente festivo" (The International, 1947: 32). La cobertura resaltó que los árbitros no quisieron cobrar remuneración alguna por llevar a cabo sus tareas, motivo por el cual toda la comunidad del colegio agradeció ese gran gesto.

\section{Conclusiones}

A partir de lo expuesto puede apreciarse que en el Colegio Ward, sitio en el oeste del Gran Buenos Aires se llevó adelante un ambicioso programa en materia de cultura física, tal como se lee en las páginas de la revista estudiantil. Sí bien en el plano nacional el gobierno dirigido por Juan Domingo Perón no ahorró esfuerzos en el mismo sentido invirtiendo en la 
construcción de infraestructura, realizando torneos intercolegiales, infantiles e incluso los primeros Juegos Panamericanos de la historia en el año 1951, se pudo comprobar que la institución abordada tenía características propias, lo cual permite considerar ese fomento a la cultura física como intrínseco a la cultura escolar de la institución. Por cierto, el espacio privilegiado en que se desenvolvía el colegio, con amplio espacio para la práctica de los deportes, el hecho de ser una escuela mixta, de contar con un fuerte sentido de pertenencia y los aportes que la cultura física hacían en la formación de ciudadanos sanos y fuertes, fueron factores que ayudaron a la difusión de las actividades físicas. Siguiendo a Alicia Civera (2008), es necesario advertir que las disposiciones oficiales no necesariamente se transforman en prácticas, puesto que la realidad educativa transcurre, en muchos casos, por carriles autónomos. La institución analizada da cuenta de ello.

\section{Bibliografía}

Aisenstein, Angela (2006), "La educación física escolar en Argentina. Conformación y permanencia de una matriz disciplinar, 1880-1960", tesis de doctorado, Universidad de San Andrés, Buenos Aires.

Ball, Stephen (1990), Politics and policy making in education. Explorations in policy sociology, Routledge, London.

Beer, David (2014), "La configuración de las tradiciones del Instituto Nacional de Educación Física de Buenos Aires y su resignificación en el contexto de la última dictadura militar", tesis de doctorado, FLACSO, Buenos Aires.

Boletín de Comunicaciones n79 (1946), Ministerio de Justicia e Instrucción Pública, Buenos Aires, Argentina.

Civera, Alicia (2008), La escuela como opción de vida. La formación de maestros normalistas rurales en México, 1921-1945, El Colegio, México.

Elias, Norbert, y Dunning, Erie (1992), Deporte y ocio en el proceso de civilización. Fondo de Cultura Económica. Madrid.

Finocchio, Silvia (2013), "Un tesoro inexplorado: los periódicos escolares en la Argentina", Historia de la Educación, vol.17, n.40, pp.27-54.

Galak, Eduardo (2012), "Del dicho al hecho (y viceversa). El largo trecho de la construcción del campo de la formación profesional de la Educación Física en Argentina", tesis de doctorado, Universidad Nacional de La Plata, Argentina.

Gleyse, Jacques (2011), "La metáfora del cuerpo máquina en la Educación Física en Francia". Scharagrodsky, Pablo, La invención del "homo gymnasticus". Fragmentos históricos sobre la educación de los cuerpos en Occidente. Prometeo, Buenos Aires, Argentina, pp.41-56. 
Julia, Dominique (2001), "A cultura escolar como objeto histórico", en Revista Brasileira de História da Educação, n² 1, pp. 10-17.

Orbuch, Iván (2016), Peronismo y Educación Física. Políticas públicas entre 1946 y 1955, Miño y Dávila, Buenos Aires.

Orbuch, Iván (2018), "El rol del deporte en la formación de la mujer peronista", Tempose Espaços em Educaçao, $\mathrm{n}^{\circ}$ 10, pp. 35-66.

Pincon, Michael y Pincon Charlot, Monique (2010), Les Chettos du Gota, Seuil, París.

Prospecto publicitario, (1951), Buenos Aires, Argentina.

Revista The International, 1945-1955. Buenos Aires, Argentina.

Scharagrodky, Pablo, (2008), Gobernar es ejercitar. Fragmentos históricos de la Educación Física en Iberoamérica, Prometeo, Buenos Aires.

Segundo Plan Quinquenal de la Nación Argentina. (1953). Secretaría Técnica, Buenos Aires, Argentina.

Tiramonti, Guillermina y Ziegler, Sandra (2008), La Educación de las elites. Aspiraciones, estrategias y oportunidades. Paidós, Buenos Aires.

Torrón, Ana (2015), Gimnasia y Deporte en el Instituto Superior de Educación Física (1939 - 1973), su configuración y su enseñanza, tesis de maestría, Universidad de la República, Uruguay.

Tyac, David y Cuban, Larry (1995), En busca de la utopía. Un siglo de reformas de las escuelas públicas, Fondo de Cultura Económica, Buenos Aires.

Viñao Frago, Antonio (1995), "Historia de la educación e historia cultural: posibilidades, problemas, cuestiones", en Revista Brasileira de Educação, nº 0, pp. 8-20. 